\title{
SHOULD BUDAPEST STOCK EXCHANGE MARKET INVESTORS BE AFRAID OF BREXIT: A WAVELET COHERENCE ANALYSIS
}

\author{
Harun ERCAN*, Mert MENTES \\ Financial Research Center, Corvinus University of Budapest, \\ Fovam ter, 1092 Budapest, Hungary \\ *E-mail: harunerc@gmail.com
}

\begin{abstract}
Purpose - this study investigates the stock market co-movements among three countries to observe the contagion which can be increased during Brexit.

Research methodology - Wavelet method used in this study to illustrate exciting dynamics of the coherence between the UK, German and Hungarian stock markets since 2012.

Findings - the results show that the connection of the Budapest Stock Exchange and London Stock Exchange Market Indices is increasing recently. The coherence between DAX and FTSE appears to be very high lately. This supports the idea that may affect Hungarian markets.

Research limitations - because of the nonstationary of the time series such as stock exchange market data, it is essential to have a measure of correlation or coherence such as wavelet. The days on which both markets were open could be used to see the co-movements better.

Practical implications - this paper aims to show if there is a particular sign for a co-movement between markets and therefore warns the investors about a dramatic change which might appear after Brexit. After the decision of Brexit, investors in many markets do not know what their future position should be. Although it is still unknown how FTSE will react when Britain leaves the EU, as a major country of the Union it may create some sanctions. These sanctions may harm many stock markets as it may create new fluctuations.

Originality/Value - this study used a technique called wavelet to search the possible effects of Brexit in an Eastern economy. The novelty of this paper is coming from the application of the wavelet method by using financial market data, that enables us to understand the relations among stock markets during no crisis time. Because many studies focus on big markets in Europe such as British, German and French stock markets, the main contribution of this study fills the gap in the literature on the effects of Brexit in an Eastern Europe Economy.
\end{abstract}

Keywords: wavelet coherence, Brexit, BUX, DAX, FTSE, stock markets, correlation.

JEL Classification: C22, C40, E32, F30, G15.

Conference topic: Contemporary Financial Management.

\section{Introduction}

The connection between stock markets is increasing continuously. And also the openness of stock exchange markets gets higher. Notably, in emerging countries, demand from international markets aiming portfolio diversification leads growth in the liquidity and becoming hard to reject. However, this integration and co-movement are also causing the failure of portfolio diversification. The crisis started in 2007 and spread to European markets showed us diversification might be low during crises, because of the rise in the interconnection of markets during this period (Baruník \& Vácha, 2013).

The aim of this paper is to assess the coherence between FTSE, DAX and Hungarian stock market to make investors aware of the risks that may arouse after Brexit. As Brexit may cause sanctions in the stock market of developed countries, this may have an impact on smaller economies. Therefore, this analyses also helps to observe the changes in the correlation over the examined period.

On 23 June 2016, the United Kingdom voted in a referendum not to be a member country in the European Union. It has been observed that stock prices reacted dramatically in the following day of the decision. The results of Brexit has not yet been fully seen because there is still debate what would be the impact and which countries and which 
companies would be affected by Brexit The uncertainty especially in Stock Exchange Markets have not preferred a situation. This uncertainty may cause a significant movement that can create many risks in financial markets therefore in economies. When the interdependence of the Stock Markets is taken into account, we may come up with an idea asserting that UK's decision to leave the European Union (EU) will change not just the political world but also the financial markets.

From the macroeconomic perspective, Britain's Brexit referendum caused a significant increase in economic, political and social uncertainty which is expected to harm the national economy. July 2016 International Monetary Fund (IMF) forecasts presented in World Economic Outlook Update indicated GDP growth rate decrease in comparison to April 2016 projections (0.2 and 0.9 percentage point in 2016 and 2017 respectively) (IMF, World Economic Outlook Update, 2016).

Raddant (2016) studied the response of some European markets after Brexit vote. The observations showed similarities in Germany, France, Spain and Italy. The stock prices in these countries decreased dramatically. Especially in the UK and in Italy, the volatility of the stock prices showed a peak.

Ramiah, Pham, and Moosa (2017) examined the effect of the results of Brexit referendum on various sectors of the British economy. Their results showed that the impact shows variations according to the sector. The findings show in detail that the banking sector has been affected adversely. Oehler, Horn, and Wendt (2017) performed an event study to analyse the short-term stock price effects and the impact of firm-level internationalisation. Their study demonstrated a high degree of market efficiency because of the quick adjustment of stock prices at the international level.

Anaraki (2018) studied stock exchange market volatility and ECB reaction after Brexit. In the study, possible effects of Brexit on the volatility of British FTSE, German DAX, and French CAC indexes is investigated with econometric models. In the second part of the study, the VAR model was employed to see if there is a possibility for ECB to neutralise the negative effects of stock market volatility on macroeconomic fundamentals.

This study focuses on British (FTSE), Hungarian (BUX), and German (DAX) stock indices, as it is primarily interested in the possible impact of Brexit in Budapest Stock Exchange Market. The selected low volatile term enables us to investigate the movements during a non-crisis period and makes it possible to observe the natural coherence in markets. Because of the importance of forecasting the effects of future term volatilities in financial markets, this study seems to be quite imminent. This study fills the gap in the literature to see the possible impacts of Brexit in an Eastern European country.

\section{Literature review}

Egert and Kocenda (2007) studied some Eastern and Western Europe stock market co-movements with high-frequency data. Their research includes Hungarian, Czech, Polish, German, French, and UK stock exchange markets and covers the years 2003, 2004 and 2005. Their findings support that the correlations for daily stock index values are much higher than for high-frequency data. Connolly, Stivers, and Sun (2007) studied the U.K., US, and German stock and bond markets to illustrate co-movements during high and low volatility periods. Findings of the study support that the coherence is higher when there is low volatility. On the other hand, stock-bond co-movements tend to be positive (negative) following low (high) implied volatility days.

Gilmore, Lucey, and McManus (2008) investigated the co-integration in the Central and Eastern European stock markets. Their findings support that although the co-integration is strong, the signs of convergence to Western Europe are diminishing especially after EU accession. Hanousek and Kocenda (2009) also studied Central and Eastern European stock markets. The findings of the study support the idea that developed economies strongly influence Eastern European countries stock markets.

Candelon, Piplack, and Straetmans (2008) studied investors interests according to the portfolio diversification point of view. They observe that the short-term investors are likely to focus on the co-movement of stock returns at higher frequencies; therefore, on short-term fluctuations, however, concentrate on the long-term investors are on the long-term fluctuations. Morana and Beltratti (2008) investigated the stock markets movements of the U.K., the US, Japan, and Germany. Their findings also supported an increasing co-movements between 1973 and 2004.

Madaleno and Pinho (2012) employed Coherence Morlet Wavelet to investigate international stock market indices co-movements. They used data from 4 indices: FTSE100, DJIA30, Nikkei225, and Bovespa. Their findings support that coherence among indices are high but not at the same level across scales. They also mention that local events affect that market quickly, but there is a significant time delay for the impact on other market indices. Moreover, they also draw attention to the high correlation in markets which are geographically and economically closer.

Czech stock market and the STOXX50 index has been analysed by Gjika and Horváth (2013). The correlations between markets observed to be higher during the recent financial crisis. Kristoufek (2015) used Wavelet Analysis to indicate the main drivers of Bitcoin prices. According to the results of the wavelet analysis, Bitcoin forms a unique asset possessing properties of both a standard financial asset and a speculative one.

Jammazi and Reboredo (2016) examined the dependence and risk management in oil and stock markets. They employed a Wavelet cross-correlation and $3 \mathrm{~d}$ copula densities analysis. Their findings support that dependence is increasing after the financial crisis. Khalfaoui, Boutahar, and Boubaker (2015) analysed the relation of the crude oil 
market (WTI) and stock markets of the G-7 countries. They employed multivariate GARCH models and wavelet analysis. The study showed that there is evidence of volatility spillovers between oil and stock markets, as well as time-varying correlations for various market pairs.

Moya-Martínez, Ferrer-Lapena, and Escribane-Sotos (2015) used a wavelet to analyse the relationship between interest rates and the stock market in Spain. The results illustrated a significant interest rate sensitivity for Spanish industries. Mensi, Hammoudeh, and Tiwari (2016) examined the evidence on hedges for Gulf stock markets. They employed a wavelet-based quantile method to analyse the dynamic tail dependence structure. The results of the study show that there is an insignificant dependence on the short investment horizon. However, results also supported that at the middle and long investment horizons strong asymmetric dependence is found.

Albulescu, Goyeau, and Tiwari (2015) assessed the level of co-movements among stock markets of the PIIGS and FTSE and DAX. They employed the continuous wavelet transform which is a time-frequency approach. The results support that correlation is high especially in the short run when there is financial distress. Reboredo, Rivera-Castro, and Ugolini (2017) studied co-movement and causality between oil and renewable energy stock prices by using continuous and discrete wavelet technique. The reason for employing technique is to get dynamic correlations over time and for different time scales.

Das and Kannadhasan (2018) studied the relationship between bitcoin prices and global factors. To analyse this relationship, they used the wavelet-based technique to display the behaviour of bitcoin and stock index, economic policy uncertainty, gold spot prices, implied volatility and crude oil prices in a time-frequency domain. The results of the study showed in the short run that relation is ignorable. However, in the medium or long term, there is an impact especially from oil prices to bitcoin.

The literature review shows that studies related to Brexit focus mainly on big economies in Europe. However, relatively small economies may also have an impact causing the new movements of the European Union financial institutions. This analyses, therefore, aims to explain the possible effects of Brexit on Hungarian stock exchange market to make investors well aware of the risks that may arouse from sanctions.

\section{Methodology - Wavelet coherence}

\subsection{Wavelet}

This study has employed a bivariate framework called wavelet coherence. Wavelet coherence is a very advantageous technique when the co-movement between two-time series is studied. In this research, continuous wavelet analysis tools are used, mainly wavelet coherence, to measure the degree of local correlation between time series in the timefrequency domain and wavelet coherence phase differences. To provide a better explanation for the wavelet coherence analysis, wavelet a real-valued square integrable function, $\psi \epsilon L^{2}(R) 1$, is defined as;

$$
\psi_{u j}(t)=\frac{1}{\sqrt{j}} \psi \frac{t-u}{j}
$$

$\frac{1}{\sqrt{j}}$ in this equation implies a normalisation factor providing a unit variance of the wavelet $\left(\|\psi\|^{2}=1\right)$. U and $\mathrm{j}$ are the control parameters in the equations, where $u$ is a location parameter and $j$ is a scale parameter. Defining how the wavelet is stretched, the scale has an inversed relation to frequency. Therefore, lower scale causes a more compressed wavelet, that can be seen as higher frequencies of a time series. The admissibility condition needs to be satisfied. The admissibility condition ensures reconstruction of a time series from its wavelet transform. The condition in the second equation implies that the wavelet does not have a zero frequency component and so the wavelet has zero mean.

$$
C_{\psi}=\int_{0}^{\infty} \frac{|\psi(f)|^{2}}{f} d f<\infty
$$

\subsection{The continuous wavelet transform}

$W_{x}(\mathrm{u}, \mathrm{j})$ can be obtained with the projection of a specific wavelet $\psi($.$) onto the examined time series \mathrm{x}(\mathrm{t}) \in L^{2}(R)^{1}$, i.e.,

$$
W_{x}(u, j)=\int_{-\infty}^{\infty} x(t) \frac{1}{\sqrt{s}} \cdot\left(\frac{\overline{t-u}}{j}\right) d t
$$


It is eminent that the continuous wavelet transform has the ability to decompose and then subsequently perfectly reconstruct a time series

$$
x(t)=\frac{1}{C} \int_{\psi}^{\infty}\left[\int_{0}^{\infty} W_{x}(\mathrm{u}, \mathrm{j}) \psi_{u, j}(t) d u\right] \frac{d j}{j^{2}} \quad \mathrm{~s}>0 .
$$

Moreover, this transform allows information about the time and frequency of the original series. This transformation measures the size of the local correlation between time series. Equation (4) ensures the possibility of recovering $\mathrm{x}(\mathrm{t})$ from its wavelet.

$$
\|\mathrm{x}\|^{2}=\frac{1}{C_{\psi}} \int_{0}^{\infty}\left[\int_{-\infty}^{\infty}\left|W_{x}(\mathrm{u}, \mathrm{j})\right| d u\right] \frac{d j}{j^{2}}
$$

\subsection{The wavelet coherence}

Definition of the cross wavelet power of two-time series $x(t)$ and $y(t)$ is as follows:

$$
W_{x y}(u, j)=W_{x}(u, j) \cdot W_{y} \cdot(u, j) .
$$

In this formula, $W x(u, s)$ and $W y(u, s)$ represent continuous wavelet transforms of time series $x(t)$ and $y(t)$. The star $(*)$ signifies a complex conjugate, parameter $\mathrm{u}$ allocates a time position, and parameter $\mathrm{j}$ symbolises the scale parameter. A low wavelet scale denotes the high-frequency part of the time series - a short investment horizon (Torrence \& Webster, 1999).

Whenever the time series exhibit a high common power, the cross-wavelet power reveals areas in the timefrequency space. In the co-movement analysis, we search for areas where the two-time series in the time-frequency space co-movement, but do not necessarily have high power. A useful wavelet technique for finding these comovements is wavelet coherence.

Torrence and Webster (1999) defines the squared wavelet coherence coefficient as

$$
R^{2}(u, j)=\frac{\left.\left.\left.\left.\left.\left.\left.\mid S\left(j^{-1} W_{x y}(u, j)\right)\right] \mid\right]^{2}\right]\right)\right)\right)\right)}{\left.\left.\left.\left.\left.S\left[j^{-1}\left(W_{x}(u, j)\right)^{2}\right]\right]\right]\left.S\left[j^{-1} \mid W_{y}(u, j)\right)\right|^{2}\right]\right]\right]} .
$$

In this formula, S represents a smoothing operator. The coefficient $R^{2}(\mathrm{u}, \mathrm{j})$ lies in the interval [0, 1]. When there is a low correlation, the $R^{2}$ becomes closer to zero, whereas stronger correlation is shown with the values closer to one. Therefore, $R^{2}$ explains the local linear correlation between two stationary time series at each scale and is analogous to the squared correlation coefficient in linear regression. The following formula is showing the phase differences according to Torrence and Webster (1999) definition:

$$
\theta_{x y}(u, j)=\tan ^{-1}\left(\frac{\mathcal{F}\left\{S\left(j^{-1} W_{x y}(u, j)\right)\right\}}{\mathfrak{R}\left\{S\left(j^{-1} W_{x y}(u, j)\right)\right\}}\right) .
$$

$\mathcal{F}$ is an imaginary and $\mathfrak{R}$ is a real part operator in this formulation. Black arrows in the wavelet coherence figures with significant coherence display the Phase differences. Once the two analysed time series move together on a particular scale, the arrows direct to the right showing the positive correlation. On the other hand, if the correlation is negative between time series, then the arrows lead to the left. Then the arrows point to the left.

\section{Data and statistical issues}

This study investigates the financial contagion because it may harm the global economy about portfolio risk management, the formulation of monetary and fiscal policy, and strategic asset allocation and pricing. To analyse the possible impacts of Brexit, the co-movements of three stock exchange markets has been examined for a five-year term. Daily closing prices measured in domestic currencies of stock market indices, FTSE100, DAX, and BUX are used in this analysis between 01.Jan.2012 and 31.Dec.2016. stock price data is provided by Bloomberg. Because of the different working days in countries, only closing prices data of 1230 days are used.

Following tables are providing a descriptive analysis of the data. The Table 1 summarises the summary statistics for the daily return for the daily returns of stock markets. The Jarque-Bera test statistic (JB) has been used to check the normality by STATA. It is proving that index values are not normally distributed. 
Table 1. Descriptive analysis

\begin{tabular}{|c|c|c|c|c|c|c|c|}
\cline { 4 - 8 } \\
\cline { 5 - 9 } \\
Variable & Obs & Mean & Std. Dev. & Pr(Skewness) & Pr(Kurtosis) & $\begin{array}{c}\text { adj } \\
\text { chi2(2) }\end{array}$ & Prob>chi2 \\
\hline BUX & 1230 & 67.7783 & 11.4321 & 0 & 0.0006 &. & 0 \\
\hline FTSE & 1230 & 7999.08 & 741.919 & 0 & 0.3749 & 50.81 & 0 \\
\hline DAX & 1230 & 9180.02 & 1541.79 & 0.0003 & 0 &. & 0 \\
\hline
\end{tabular}

In Table 2, it is investigated that FTSE and DAX has a very high unconditional correlation. While FTSE and BUX have a very low level of correlation, the relationship between FTSE and BUX is only 0.0963 , whereas the correlation between FTSE and DAX is 0.8882 . The correlation matrix below displays general information about the correlation between markets over a period. However, it does not give information about the lag of coherence or impact causing from one market to the other. On the other hand, it is impossible to see the changes in the correlation during this period from a correlation matrix.

Table 2. Correlation matrix

\begin{tabular}{|c|c|c|c|}
\hline & BUX & FTSE & DAX \\
\hline BUX & 1 & & \\
\hline FTSE & 0.0963 & 1 & 1 \\
\hline DAX & 0.4469 & 0.8882 & \\
\hline
\end{tabular}

\section{Results and discussion}

Following figures are showing the wavelet coherence between stock market indices of three countries. Arrows indicate the phase difference, and it enables us to understand the details about delays of oscillation of the two examined time series. In figures, arrows have different meanings. Primarily, it shows that there is a correlation between the time series. But to understand the relationship more in detail, the direction of the arrow should be observed. For the positive correlation between series, Matlab uses the arrows point to the right. On the other hand, arrows directed to the left when there is a negative correlation and time series are anti-phase. And finally, when the arrows are pointing up means that the first time series leads the second one, an arrow pointing down indicates that the second time series lead the first one.

The figures are arranged to show the data regarding periods rather than frequency because it is more suitable for our research. 0.50 Magnitude Squared Coherence is used for the analysis. When the wavelet coherence are valued close to " 1 ", it indicates higher correlation (illustrated by warm colour in the figures), whereas when the values are near " 0 " (white colour in figures) that represents low or no correlation. The significant area is shown as bordered with a dashed white line. The squared wavelet coherence coefficient can be regarded as a local linear correlation measure between two- time series in the time-frequency space.

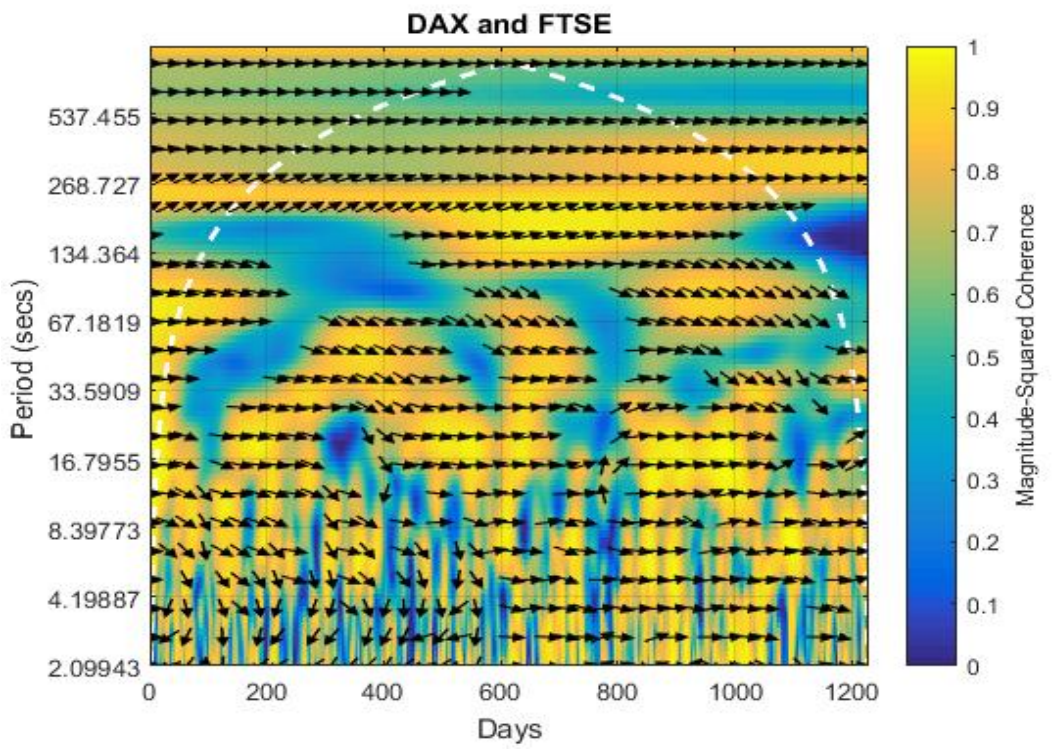

Figure 1. DAX and FTSE wavelet analysis 
As we already observed in the data analysis, the high correlation between DAX and FTSE could be seen in Figure 1. Now, wavelet coherence analysis allows us to see this correlation on a daily base. As we also see from Figure 1 that DAX and FTSE are positively correlated because the directions of the arrows are towards the right. And also we can deduce that data from FTSE is leading DAX index values particularly in the first 600 days of the period.

Figure 1 displays us a precise picture that the coherence between DAX and FTSE is very high throughout the examined period. As we could see from Figure 1, yellow areas are very high with the main arrows to the right. This is a sign for a high positive correlation between these stock markets. The figure helps us understand that portfolio diversification seems very difficult if the investors would like to use these stock markets.

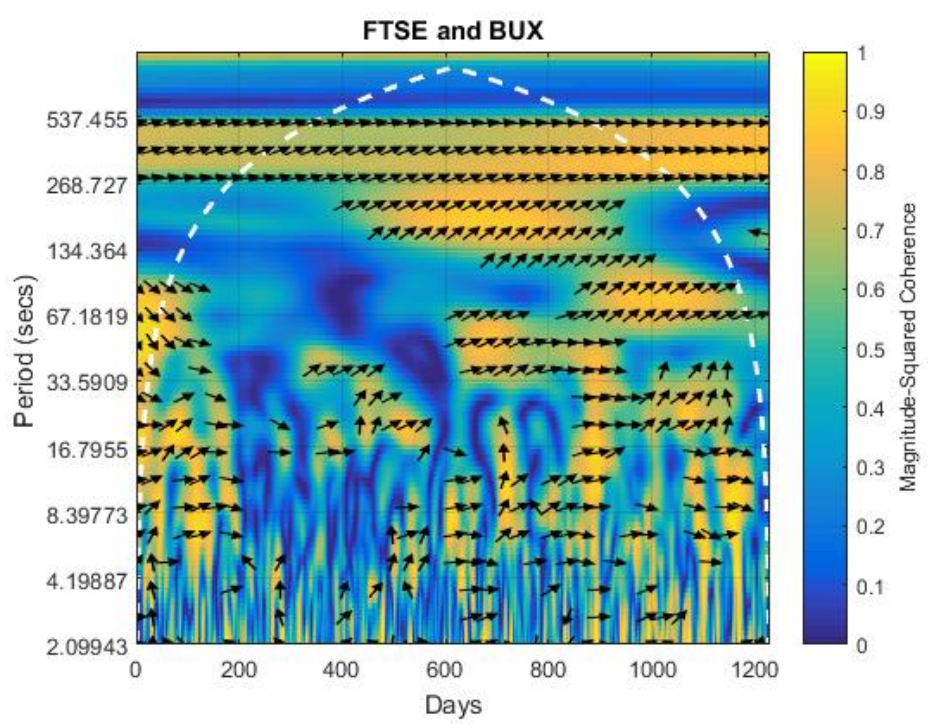

Figure 2. BUX and FTSE wavelet analysis

The second figure allows us to investigate the coherence between the Budapest Stock Exchange and London Stock Exchange. According to the descriptive analysis in SPSS, the correlation between the time series was relatively very low. As we could see from Figure 2, coherence is relatively small in the first half of the examined period. However, starting from mid-2014, we could observe arrows to the right and upwards. It enables us to summarise that the relationship is increasing especially in the last two years and FTSE index values are leading BUX index values. This is the period when the Brexit rumours have started, and financial markets have gained more volatility because of forecasting the future of the market was becoming harder.

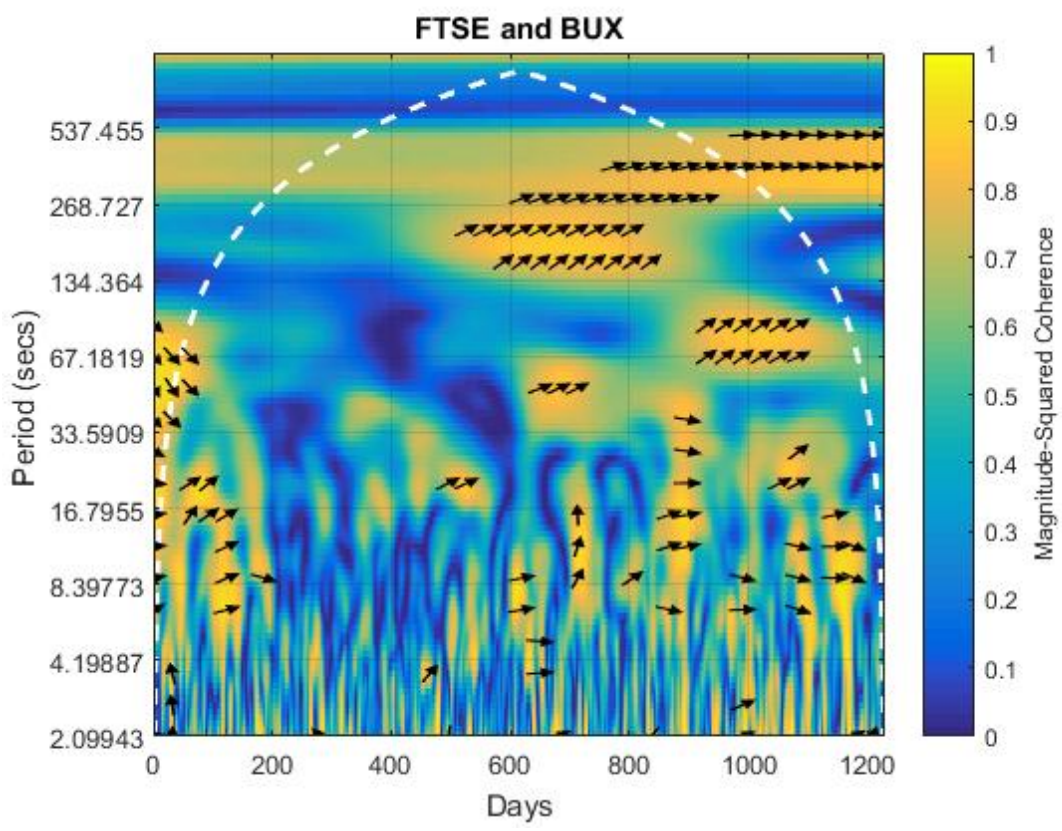

Figure 3. BUX and FTSE wavelet analysis in high magnitude 
In this 3rd figure, the wavelet coherence is shown with phase estimates. This plot illustrates the relative lag between the two Stock Exchange market index time series only where the magnitude-squared coherence exceeds 0.75 . So in this figure, we can distinctly see the increasing impact of FTSE on BUX approximately in the last two years. This figure is the same as in Figure 2. However, with the help of high magnitude, observation of increasing coherence between two markets is more straightforward in Figure 3.

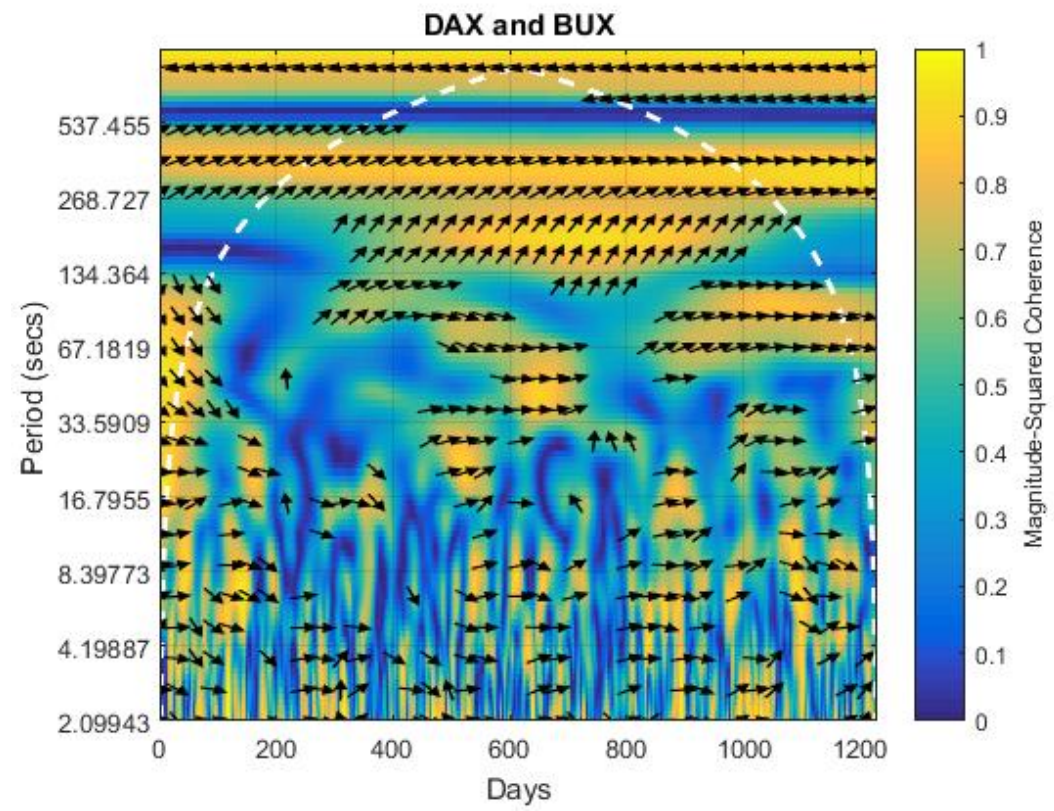

Figure 4. BUX and DAX wavelet analysis

Figure 4 displays the coherence between the German Stock Exchange and Budapest Stock Exchange index values over the same 5-year period. The impact of DAX on BUX values are visible and cannot be neglected although the coherence is not very strong. The arrows upwards allow us to conclude that the main effect is from DAX towards BUX. It illustrates that changes volatility in DAX will have an impact on BUX with a lag. We could also observe that correlation is mainly positive.

To summarise, the figures above displays a high coherence especially between DAX and FTSE. The level of coherence between DAX and BUX is also very high throughout the period examined in this research. On the other hand, BUX is not showing any coherence until 600 days of the observed period.

\section{Conclusions}

For this study between three countries' time series, bivariate wavelet technique called wavelet coherence is employed. The area under the white arc of the wavelet coherence graphics shows significant movements. While warmer colours imply higher coherence, blue is showing no correlation. The arrows indicate the lag between indices.

Consequences of this study show that the relations between stock exchange market indices are stable but not homogeneous. It can be seen that some movements are with a significant time delay. Results also support that German and British economies have higher coherence and therefore the co-movements are more visible. The results of this study also show that the Hungarian Stock Exchange market has similar movements with FTSE in the last two years. Although the coherence is not as high as the coherence between DAX and FTSE, as we can observe from the Figures 2 and 3, the increasing coherence lately, Hungarian Stock Exchange Market investors should be aware of the risk that may arouse from Brexit. It is eminent to mention that increasing coherence in European financial markets may lead negative impact of correlations to spread over smaller economies. Besides that, BUX can be indirectly affected by Brexit as because the very high coherence of FTSE and DAX (as shown in Figure 1) may cause fluctuations in German Economy and DAX. This study may also be extended by including more countries and stock market indices or increasing periods such as crisis.

\section{Limitation and disclosure statement}

Due to the differences in working days of the stock markets, the data has been limited with the days on which all the markets are open. There are no competing financial, professional, or personal interests from other parties. 


\section{References}

Albulescu, C. T., Goyeau, D., \& Tiwari, A. K. (2015). Contagion and dynamic correlation of the main European stock index futures markets: a time-frequency approach. Procedia Economics and Finance, 20, 19-27. https://doi.org/10.1016/S2212-5671(15)00042-8

Anaraki, N. K. (2018). Post-Brexit stock market volatility, and European Central Bank reaction function. Journal of Finance and Economics, 6(6), 237-241. https://doi.org/10.12691/jfe-6-6-5

Baruník, J., \&Vácha, L. 2013. Contagion among Central and Eastern European stock markets during the financial crisis. Czech Journal of Economics and Finance (Finance a uver), 63(5), 443-453.

Candelon, B., Piplack, J., \& Straetmans, S. (2008). On measuring synchronisation of bulls and bears: the case os East Asia. Journal of Banking and Finance, 32, 1022-1035. https://doi.org/10.1016/j.jbankfin.2007.08.003

Connolly, R., Stivers, C., \& Sun, L. (2007). Commonality in the time-variation of stock-stock and stock-bond return comovements. Journal of Financial Markets, 10, 192-218. https://doi.org/10.1016/j.finmar.2006.09.005

Das, D., \& Kannadhasan, M. (2018). Do global factors impact bitcoin prices? Evidence from wavelet approach. Journal of Economic Research, 23, 227-264.

Egert, B., \& Kocenda, E. (2007). Interdependence between Eastern and Western European stock markets: Evidence from intraday data. Economic Systems, 31, 184-203. https://doi.org/10.1016/j.ecosys.2006.12.004

Gilmore, C., Lucey, B., \& McManus, G. (2008). The dynamics of Central European equity market comovements. The Quarterly Review of Economics and Finance, 48, 605-622. https://doi.org/10.1016/j.qref.2006.06.005

Gjika, D., \& Horváth, R. (2013). Stock market comovements in Central Europe: Evidence from the asymmetric DCC model. Economic Modelling, 33, 55-64. https://doi.org/10.1016/j.econmod.2013.03.015

Hanousek, J., \& Kocenda, E. (2009). Intraday price discovery in emerging European stock markets. (CERGE-EI Working Paper Series, No. 382). https://doi.org/10.2139/ssrn.1448618

IMF, World Economic Outlook Update. (2016). Uncertainty in the Aftermath of the U.K. Referendum. Retrieved from https://www.imf.org/en/Publications/WEO/Issues/2016/12/31/Uncertainty-in-the-Aftermath-of-the-U-K

Jammazi, R., \& Reboredo, J. C. (2016). Dependence and risk management in oil and stock markets. A wavelet-copula analysis. Energy, 107, 866-888. https://doi.org/10.1016/j.energy.2016.02.093

Khalfaoui, R., Boutahar, M., \& Boubaker, H. (2015). Analyzing volatility spillovers and hedging between oil and stock markets: Evidence from wavelet analysis. Energy Economics, 49, 540-549. https://doi.org/10.1016/j.eneco.2015.03.023

Kristoufek, L. (2015). What are the main drivers of the Bitcoin price? Evidence from wavelet coherence analysis. PLoS ONE, 10(4), e0123923. https://doi.org/10.1371/journal.pone.0123923

Madaleno, M., \& Pinho, C. (2012). International stock market indices comovements: a new look. International Journal of Financial Economics, 17, 89-102. https://doi.org/10.1002/ijfe.448

Mensi, W., Hammoudeh, S., \& Tiwari, A. K. (2016). New evidence on hedges and safe havens for Gulf stock markets using the wavelet-based quantile. Emerging Markets Review, 28, 155-183. https://doi.org/10.1016/j.ememar.2016.08.003

Morana, C., \& Beltratti, A. (2008). Comovements in international stock markets. International Financial Markets, Institutions and Money, 18(1), 31-45. https://doi.org/10.1016/j.intfin.2006.05.001

Moya-Martínez, P., Ferrer-Lapena, R., \& Escribane-Sotos, F. (2014). Interest rate changes and stock returns in Spain: A Wavelet analysis. Business Research Quarterly, 23, 1-16.

Oehler, A., Horn, M., \& Wendt, S. (2017). Brexit: short-term stock price effects and the impact of firm-level internationalization. Finance Research Letters, 22, 175-181. https://doi.org/10.1016/j.frl.2016.12.024

Raddant, M. (2016). The response of European stock markets to the Brexit. Kiel Policy Brief, 100, 4-11.

Ramiah, V., Pham, H. N. A., \& Moosa, I. (2017). The sectoral effects of Brexit on the British economy: early evidence from the reaction of the stock market. Applied Economics, 49(26), 2508-2514. https://doi.org/10.1080/00036846.2016.1240352

Reboredo, J. C., Rivera-Castro, M. A., \& Ugolini, A. (2017). Wavelet-based test of co-movement and causality between oil and renewable energy stock prices. Energy Economics, 61, 241-252. https://doi.org/10.1016/j.eneco.2016.10.015

Torrence, C., \& Webster, P. J. (1999). Interdecadal changes in the ENSO-monsoon system. Journal of Climate, 12(8), $2679-2690$. https://doi.org/10.1175/1520-0442(1999)012<2679:ICITEM >2.0.CO;2 